\title{
PENERAPAN PSAK NO 14 ATAS PERSEDIAAN BARANG DAGANG (STUDI KASUS PADA PT. ASIA TENGGARA MURNI)
}

\author{
Royke Palar ${ }^{1}$, Winston Pontoh ${ }^{2}$, Sherly Pinatik ${ }^{3}$ \\ ${ }^{1,2,3}$ Fakultas Ekonomi dan Bisnis, Jurusan Akuntansi, Universitas Sam Ratulangi, Jl. Kampus Bahu Manado \\ 95115, Indonesia \\ E-mail : roykepalar.asg@gmail.com
}

\begin{abstract}
Inventories are an important active on a trading company, because it is one of component that is very active. A company in its day to day normal activities will prioritize the conversion of inventories to cash, and also to obtain profit from the margin between Cost of Goods Sold (COGS) and the product selling price. It should be known that inventories are vulnerable to product faults and thievery, damaged in store, invalid entries, invalid demand registries, items that does not match the order and other possibilities that may cause a difference on inventories on the ledger and the actual inventories on the warehouse. One to its importance, inventories has to be managed properly in accordance with the Accounting Standard that is implemented in Indonesia. The purpose of this research is to know whether or not the implementation of Inventories Accounting in PT. Asia Tenggara Murni are being implemented in accordance with PSAK 14, using descriptive analysis method, the research shows that the inventories Accounting method in PT. Asia Tenggara Murni has been implemented in accordance with PSAK No.14 which consists of recording, appraising, and full disclosure of inventories.
\end{abstract}

Keywords: accounting inventories; recording; appraising; disclosure

\section{PENDAHULUAN}

Memasuki dunia ekonomi yang semakin berkembang luas saat ini, setiap perusahaan yang bertumbuh dan berkembang memerlukan suatu pengendalian internal persediaan yang baik sehingga dapat menunjang sistem dan kelancaran kegiatan normal atau produksi perusahaan tersebut. Persediaan merupakan unsur yang paling aktif dalam perusahaan dagang dan salah satu syarat pokok yang harus dipenuhi serta dimiliki oleh suatu perusahaan didalam aktifitas perdagangan karena dalam perdagangan yang diperdagangkan adalah persediaan tersebut. Namun disisi lain persediaan sangat rentan terhadap kerusakan maupun pencurian, kerusakan, pemasukan yang tidak benar, lalai untuk mencatat permintaan, barang yang dikeluarkan tidak sesuai pesanan dan semua kemungkinan lainnya yang dapat menyebabkan catatan persediaan berbeda dengan persediaan yang sebenarnya ada di gudang. Untuk itu dibutuhkan intern persediaan yang bertujuan untuk melindungi harta perusahaan dan juga agar informasi mengenai persediaan lebih dapat dipercaya.

Di Indonesia sendiri standar akuntansi persediaan dalam suatu perusahaan telah diatur dalam Pernyataan Standar Akuntansi Keuangan (PSAK) 14, dimana PSAK 14 menjadi pedoman penerapan akuntansi persediaan perusahaan yang beroperasi di Indonesia. PT. Asia Tenggara Murni yang beralamat di Jl. Raya Maumbi No. 5 Kalawat Manado adalah perusahaan yang mendistribusikan berbagai macam produk yang sudah tidak asing di masyarakat luas terlebih khusus di daerah Sulawesi Utara, yaitu air mineral AKE, minuman kemasan Banteng, minuman kemasan New Greentea berbagai varian rasa, minuman kemasan Teh Tarik Milk Tea, Jahe 41, Yougurt Kin, berbagai jenis kerupuk, obat nyamuk lokal Sulawesi Utara Manguni, dan berbagai produk lainnya. Teknik pencatatan dan penilaian akuntansi terhadap persediaan PT. Asia Tenggara Murni adalah suatu keharusan yang mutlak 
pentingnya bagi manajemen, agar menghasilkan suatu data yang benar, sehingga tidak terjadi kesalahan dalam pelaporannya.

\section{TINJAUAN PUSTAKA}

Persediaan barang dagangan atau sering disebut sebagai persediaan terdiri atas barang-barang yang disediakan untuk dijual kepada para konsumen selama periode normal kegiatan perusahaan (Hermawan et al. 2019:131). Menurut Syakur (2015), persediaan meliputi segala macam barang yang menjadi objek pokok aktivitas perusahaan yang tersedia untuk diolah dalam proses produksi atau dijual. Keberadaan persediaan memiliki nilai strategis bagi perusahaan. Hal ini disebabkan sekitar 25\% atau lebih dari investasi yang ditanamkan dalam modal usaha berupa persediaan. Persediaan mendominasi aktiva lancar perusahaan yang merupakan modal kerja guna memutar roda persediaan (Martani et al., 2014:245). Menurut Rondonuwu et al. (2016) definisi persediaan menurut fungsinya adalah sebagai batch atau lot size inventory, fluctuation stock, dan anticipation stock. Nafarin (2014:83) menerangkan bahwa faktor yang mempengaruhi besar kecilnya persediaan bahan baku yang dimiliki perusahaan adalah anggaran produksi, harga beli bahan baku, biaya penyimpanan bahan baku digudang, ketepatan pembuatan standar pemakaian bahan baku.

Pernyataan Standar Akuntansi Keuangan (PSAK) No. 14 dalam paragraf 1 menyatakan tujuan dari PSAK adalah mengatur perlakuan akuntansi untuk persediaan. Permasalahan pokok dalam akuntansi persediaan adalah penentuan jumlah biaya yang diakui sebagai aset dan perlakuan akuntansi selanjutnya atas aset tersebut sampai pendapatan terkait diakui (Ikatan Akuntan Indonesia, 2014). Menurut Hery (2016:242), dalam akuntasi dikenal 3 (tiga) metode yang dapat digunakan dalam menghitung besarnya nilai persediaan akhir, yaitu metode first-in, first-out (FIFO), metode last-in, first-out (LIFO), dan metode biaya rata-rata (average cost method).

Menurut Samryn (2015:85-86), metode pencatatan berkaitan berkaitan dengan prosedur perekaman kuantitas dan mutasi masuk dan keluar serta saldo persediaan. Dua metode pencatatan persediaan yang lazim digunakan adalah metode fisik dan metode perpetual.

a. Metode fisik. Menurut Sujarweni (2019:84), perhitungan dengan cara melihat secara langsung wujud/fisik barang yang dimiliki saat itu (stock opname). Persediaan tidak dicatat setiap saat. Metode ini biasanya digunakan untuk perusahaan yang menjual produk banyak dan harga per satuannya relatif murah. Metode fisik/periodik ini menyatakan, bahwa jumlah persediaan ditentukan secara berkala (periodik) dengan melakukan perhitungan fisik dan mengalikan jumlah unit tersebut dengan harga satuan untuk menghitung nilai persediaan yang ada pada saat itu (Kartikahadi, 2012:332).

b. Metode perpetual. Menurut Bahri (2019:326), pada metode perpetual (perpetual method) transaksi pembelian maupun semua transaksi yang berhubungan dengan pembelian, seperti retur pembelian, potongan pembelian, dan biaya angkut pembelian dicatat pada rekening persediaan barang dagangan. Rekening persediaan barang dagangan selalu berubah karena adanya pembelian, penjualan, dan transaksi lain yang berhubungan dengan transaksi pembelian maupun penjualan. Pada saat transaksi penjualan, selain mencatat nilai penjualan juga diikuti dengan pencatatan harga pokok barang yang terjual dengan dicatatkan pada rekening beban pokok penjualan. Metode perpetual ini menyatakan catatan persediaan selalu dimutakhirkan (updated) setiap kali terjadi transaksi yang melibatkan persediaan, sehingga perusahaan selalu mengetahui kuantitas dan nilai persediaannya setiap saat. Setiap kali dilakukan pembelian barang, maka perusahaan akan mendebit akun persediaan (Kartikahadi, 2012:332).

Menurut Hery (2016:236), pengendalian internal atas persediaaan mutlak diperlukan karena aset ini tergolong cukup lancar. Tujuan pengendalian internal atas persediaan yaitu 
untuk mengamankan atau mencegah aset perusahaan (persediaan) dari tindakan yang tak di inginkan seperti pencurian, penyelewengan, penyalahgunaan dan kerusakan serta menjamin keakuratan (ketepatan) penyajian persediaan dalam laporan keuangan. Di dalamnya, termasuk pengendalian atas keabsahan transaksi pembelian dan penjualan barang dagangan.

Menurut Hery (2016:258), persediaan disajikan sebagai aset lancar dalam laporan keuangan. Menurut Rianto et al. (2019), kenaikan atas harga pokok penjualan cenderung dapat mengakibatkan kerugian pada perusahaan. Sebaliknya, Maramis et al. (2020) menemukan bahwa nilai harga pokok penjualan yang lebih kecil cenderung meningkatkan laba perusahaan. Pontoh dan Budiarso (2018), Saerang dan Pontoh (2019), dan Budiarso dan Pontoh (2019) menemukan bahwa ketidaktepatan dalam penentuan harga pokok penjualan dapat menyebabkan perusahaan tidak memiliki harga jual yang tidak kompetitif. Menurut Hery (2016:259-263), teknik estimasi persediaan digunakan untuk menentukan nilai persediaan ketika catatan persediaan perpetual tinggal diselenggarakan dan perhitungan fisik atas persedian dirasakan tidak praktis atau tidak memungkinkan untuk dilakukan. Dalam akuntansi besarnya nilai persediaan dapat diestimasi dengan menggunakan metode laba kotor (gross profit method) atau metode harga ecer/harga jual (retail method).

Baramuli dan Pangemanan (2015) menunjukkan bahwa sistem administrasi dealer telah di ubah dari sistem manual menjadi terkomputerisasi yang menghasilkan output yang berguna bagi setiap pengguna informasi tersebut sehingga hal tersebut menyiratkan adanya unsur pengendalian internal. Tuerah (2014) menunjukan bahwa pengendalian dan pengadaan persediaan bahan baku ikan tuna CV. Golden KK sudah efektif dalam memenuhi permintaan konsumen karena perusahaan tidak mengalami kehabisan persediaan bahan baku dan total biaya persediaan dengan metode $E O Q$ lebih kecil dibandingkan dengan metode yang digunakan perusahaan. Tamodia (2013) menunjukkan bahwa sistem pengendalian persediaan barang dagangan telah efektif karena penerimaan dan penyimpanan barang pencatatan dan otoritas dilakukan oleh fungsi yang berbeda.

\section{METODE PENELITIAN}

\subsection{Jenis dan sumber data}

Jenis penelitian studi ini menggunakan deskriptif kualitatif yaitu metode yang menganalisis masalah dengan cara mendeskripsikannya pada data-data yang sudah ada, berupa catatan persediaan barang dan data penjualan untuk memberikan gambaran maupun uraian jelas dan mengevaluasi penerapan PSAK No. 14 terhadap akuntansi persediaan pada PT. Asia Tenggara Murni Manado Sulawesi Utara. Tempat dan waktu penelitian ini dilakukan pada PT. Asia Tenggara Murni yang beralamat di Jl. Raya Maumbi No. 5 Kalawat Kabupaten Minahasa Utara Sulawesi Utara. Jenis data yang digunakan dalam penelitian ini adalah data kualitatif dan data kuantitatif, dimana:

1. Data kualitatif, merupakan data yang digunakan dalam bentuk uraian atau deskriptif mengenai gambaran umum perusahaan.

2. Data kuantitatif, merupakan data yang disajikan dalam bentuk angka dan tabel.

Sumber data dalam penelitian ini adalah data primer, yaitu data yang diperoleh langsung dari perusahaan tempat penelitian dalam hal ini adalah PT. Asia Tenggara Murni. Data yang dimaksud adalah berupa data yang bersangkutan dengan persediaan barang dagangan. Metode analisis penelitian ini menggunakan analisis kualitatif desriptif dengan tujuan untuk menggambarkan fakta atau sifat dari suatu keadaaan yang ada pada waktu penelitian dengan mempelajari gejala-gejala tertentu. Teknik pengumpulan data dilakukan dengan cara wawancara dan dokumentasi. Teknik analisis dalam penelitian ini menggunakan metode deskriptif, yaitu metode yang dilakukan dengan cara mengumpulkan data, menyajikan data, dan menganalisis data dengan melakukan perbandingan antara teori-teori dengan data objektif yang terjadi. 


\section{HASIL PENELITIAN DAN PEMBAHASAN}

\subsection{Hasil penelitian}

Kepemilikan persediaan barang pada PT. Asia Tenggara Murni merupakan persediaan milik sendiri. Persediaan barang dagang ini di order dari perusahaan produksi lokal daerah di Manado, dan perusahaan nasional dari Surabaya dan Jakarta. Dalam melakukan pembelian persediaan barang dagang, pembayaran oleh PT Asia Tenggara Murni dilakukan secara tunai dan kredit tergantung pada kebijakan dan kesepakatan dengan penjual barang persedian yang diambil oleh manajemen. Saat menjual persediaannya kepada konsumen, PT Asia Tenggara Murni memberikan metode pembayaran terhadap konsumen untuk membayar secara tunai atau kredit sesuai kesepakatan yang ada.

Metode pencatatan persediaan barang dagang PT Asia Tenggara Murni dalam mencatat persediaan barang dagangnya mengunakan metode perpetual, yang setiap terjadinya transaksi masuk keluar barang dagang selalu dicatat di pembukuan, setiap tipe barang dagang memiliki pencatatannya masing-masing sehingga stock barang pada perusahaan dapat bisa diketahui kapan saja dan dapat mengantisipasi terjadinya kehabisan persediaan barang dagang. Metode penilaian persediaan menggunakan metode Masuk Pertama Keluar Pertama (MPKP), yang berarti barang yang masuk lebih awal adalah barang yang akan terlebih dahulu dikeluarkan dilihat dari nilai harga pokok yang pertama kali dibeli. Manajemen juga mengaplikasikan sistem ini secara fisiknya.

Pengungkapan persediaan dalam laporan laba rugi PT. Asia Tenggara Murni persediaan muncul dalam harga pokok penjualan. Dalam laporan keuangan PT. Asia Tenggara Murni, persediaan barang dagang yang ada pada akhir tahun akan disajikan kembali pada tahun berikutnya. PT Asia Tenggara Murni mencantumkan persediaan barang dagang pada neraca mencerminkan nilai barang dagang yang ada pada tanggal neraca yang merupakan akhir dari suatu periode akuntansi. Nilai persediaan yang tercantum pada neraca periode 31 Desember 2018 adalah Rp. 450.200.460.

\subsection{Pembahasan}

PSAK 14 paragraf 8 menyatakan bahwa persediaan meliputi barang yang dibeli dan dimiliki untuk dijual kembali, termasuk sebagai contoh, barang dagangan yang dibeli oleh pengecer untuk dijual kembali. Jika dibandingkan dengan PSAK 14 maka penyajian persediaan barang dagang pada PT Asia Tenggara Murni adalah meliputi barang yang dibeli dan disimpan untuk dijual kembali dalam kegiatan normal perusahaan.

Perusahaan melakukan pembelian persediaan barang dagang untuk dijual kembali agar mendapatkan keuntungan bagi perusahaan. Pada pembelian persediaan termasuk didalamnya biaya pembelian persediaan yang meliputi harga pembelian, pajak lainnya, biaya pengangkutan, biaya penanganan, dan biaya lainnya yang secara langsung diatribusikan pada perolehan barang dagang (sesuai dengan PSAK 14 dalam paragrafnya yang ke-10).

PT. Asia Tenggara Murni sesuai dengan Pernyataan Standar Akuntansi Keuangan No. 14 karena dilihat adanya penggunaan metode penilaian persediaan Masuk Pertama Keluar Pertama (MPKP) dalam pencatatan akuntansi perusahaan. Penggunaan MPKP telah sesuai dengan PSAK 14 paragraf 25 yang menyebutkan bahwa, "biaya persediaan, kecuali yang disebutkan dalam paragraf 23, dihitung dengan menggunakan rumus biaya masuk pertama keluar pertama (MPKP) atau rata-rata tertimbang".

PSAK No. 14 paragraf 36 menyatakan bahwa laporan keuangan mengungkapkan kebijakan akuntansi yang digunakan dalam pengukuran persediaan, termasuk metode arus biaya yang digunakan oleh perusahaan, sehingga pengungkapan persediaan telah sesuai dengan PSAK No.14. Hal ini ditunjukkan dengan adanya nilai persediaan akhir tahun 2018 yang tercantum pada laporan keuangan. 


\section{KESIMPULAN DAN SARAN}

\subsection{Kesimpulan}

Berdasarkan hasil penelitian maka dapat disimpulkan bahwa:

1. Metode pencatatan persediaan PT. Asia Tenggara Murni menggunakan metode perpetual.

2. Perhitungan fisik terhadap semua jenis persediaan dilakukan pada akhir tahun. Hal ini untuk membandingkan saldo yang tercatat di pembukuan apakah sudah sesuai atau tidak dengan persediaan fisik yang ada.

3. Penerapan akuntansi persediaan PT. Asia Tenggara Murni telah sesuai dengan PSAK No. 14 tentang persediaan.

\subsection{Saran}

Saran atas ini penelitian ini adalah agar perusahaan menjaga konsistensi penerapan metode arus biaya dengan menggunakan MPKP. Hal ini bertujuan agar penyajian akun persediaan dalam laporan keuangan yang disajikan mengungkapkan nilai yang wajar.

\section{DAFTAR PUSTAKA}

Bahri, S. (2019). Pengantar akuntansi berdasarkan standar akuntansi keuangan-entitas tanpa akuntabilitas publik, international financial report standard. Yogyakarta: ANDI Anggota Ikatan Penerbit Indonesia.

Baramuli, F., \& Pangemanan, S. S. (2015). Analisis sistem informasi akuntansi persediaan pada Yamaha Ima Motor Toli-toli. Jurnal Emba: Jurnal Riset Ekonomi Manajemen, Bisnis dan Akuntansi, $3(3), \quad$ 52-62. https://ejournal.unsrat.ac.id/index.php/emba/article/view/9310/8884.

Budiarso, N., \& Pontoh, W. (2019). Ipteks penghitungan harga transfer dan harga jual pada Rumah Makan Khopinos. Jurnal Ipteks Akuntansi Bagi Masyarakat, 3(1). https://doi.org/10.32400/jiam.3.1.2019.23305

Hermawan, M., Biduri, S., Hariyanto, W., \& Rahayu, R. A. (2019). Akuntansi perusahaan jasa, dagang dan manufaktur. Sidoarjo: Indomedia Pustaka.

Hery. (2016). Akuntansi dasar 1 \& 2. Jakarta: PT. Grasindo.

Ikatan Akuntan Indonesia. (2014). Standar akuntansi keuangan per efektif 1 Januari 2015. Jakarta: Graha Akuntan.

Kartikahadi, H. (2012). Akuntansi keuangan berdasarkan standar akuntansi keuangan berbasis international financial report standard buku 1. Jakarta: Salemba Empat.

Maramis, D., Ilat, V., \& Mawikere, L. (2020). Analisis penerapan pajak restoran pada penjualan (Studi kasus Rumah Makan Geprek Jo Manado). Indonesia Accounting Journal, 2(2), 87-91. https://doi.org/10.32400/iaj.27775

Martani, D., Siregar, V. S., Wardani, R., Farmawati, A., Tanujaya, E. (2014). Akuntansi keuangan menengah berbasis pernyataan standar akuntansi keuangan. Jakarta: Salemba Empat.

Nafarin, M. (2014). Penganggaran perusahaan. Jakarta: Salemba Empat.

Pontoh, W., \& Budiarso, N. (2018). Ipteks penerapan metode penentuan harga jual normal dalam penentuan harga jual jasa (studi kasus pada Usaha Photocopy Gloria Manado). Jurnal Ipteks Akuntansi Bagi Masyarakat, 2(1). https://doi.org/10.32400/jiam.2.1.2018.23523

Rianto, R., Karamoy, H., \& Wangkar, A. (2019). Analisis perhitungan harga pokok penjualan meter pascabayar dan meter prabayar dalam menggunakan metode variable cost pada PT. PLN (Persero) ULP Manado Selatan. Indonesia Accounting Journal, 1(1), 31-38. https://doi.org/10.32400/iaj.25743 
Rondonuwu, F., Pangemanan, S. S., \& Mawikere, L. M. (2016). Evaluasi penerapan metode persediaan berdasarkan metode Masuk Pertama Keluar Pertama (MPKP) pada PT. Honda Tunas Dwipa Matra Manado. Jurnal Emba : Jurnal Riset Ekonomi Manajemen, Bisnis dan Akuntansi. 4(4), 268-278. https://ejournal.unsrat.ac.id/index.php/emba/article/view/13720

Saerang, D., \& Pontoh, W. (2019). Ipteks sistem persediaan dalam penentuan harga pokok penjualan bagi usaha kecil menengah di Kecamatan Malalayang I Barat Kota Manado. Jurnal Ipteks Akuntansi Bagi Masyarakat, 3(2). https://doi.org/10.32400/jiam.3.2.2019.24005

Samryn. L. M., (2015). Pengantar akuntansi buku 2. Jakarta: Raja Grafindo Persada.

Sujarweni. V. W. (2019). Pengantar akuntansi metode pencatatan dalam perusahaan dagang. Yogyakarta: Pustaka Baru Press.

Tamodia. W, (2013). Evaluasi penerapan sistem pengendalian intern untuk persediaan barang dagangan pada PT. Laris Manis Utama cabang Manado. Jurnal Emba: Jurnal Riset Ekonomi Manajemen, Bisnis dan akuntansi. 1(3), 20-29. https://ejournal.unsrat.ac.id/index.php/emba/article/view/1366/1077

Syakur, A. S. (2015). Intermediate accounting. Jakarta: Pembuka Cakrawala.

Tuerah, M. C. (2014). Analisis pengendalian persediaan bahan baku ikan tuna pada CV.Golden KK. Jurnal Emba: : Jurnal Riset Ekonomi Manajemen, Bisnis dan Akuntansi. 2(4), 524-536. https://ejournal.unsrat.ac.id/index.php/emba/article/view/6360. 